\title{
The role of glomeruli in the neural representation of odours: results from optical recording studies
}

\author{
C. Giovanni Galizia *, Randolf Menzel \\ Institut für Biologie-Neurobiologie, Fachbereich Biologie, Chemie, Pharmazie, Freie Universität Berlin, Königin Luise Strasse 28-30, 14195 \\ Berlin, Germany
}

Received 13 March 2000; accepted 19 June 2000

\begin{abstract}
Odours are received by olfactory receptors, which send their axons to the first sensory neuropils, the antennal lobes (in insects) or the olfactory bulb (in vertebrates). From here, processed olfactory information is relayed to higher-order brain centres. A striking similarity in olfactory systems across animal phyla is the presence of glomeruli in this first sensory neuropil. Various experiments have shown that odours elicit a mosaic of activated glomeruli, suggesting that odour quality is coded in an 'across-glomeruli' activity code. In recent years, studies using optical recording techniques have greatly improved our understanding of the resulting 'across-glomeruli pattern', making it possible to simultaneously measure responses in several, often identifiable, glomeruli. For the honeybee Apis mellifera, a functional atlas of odour representation is being created: in this atlas, the glomeruli that are activated by different odorants are named. However, several limitations remain to be investigated. In this paper, we review what optical recording of odour-evoked glomerular activity patterns has revealed so far, and discuss the necessary next steps, with emphasis on the honeybee. (C) 2000 Elsevier Science Ltd. All rights reserved.
\end{abstract}

Keywords: Olfactory glomeruli; Antennal lobe; Olfactory bulb; Optical imaging; Apis mellifera; Review

\section{Introduction}

Sensory stimuli are represented in the nervous system as activity patterns, which often reflect physical properties of the stimulus. Retinotopy and tonotopy in the thalamus and the cortex are well-studied examples. The somatosensory map in the cortex is another example. The world of smell and its neural representation is less well understood. Other than in vision, hearing and touch, the receptors for odorants come in a large number of functional classes. For mammals it is estimated that more than 1000 different receptor types are expressed (Ressler et al., 1994; Vassar et al., 1994), for insects that

\footnotetext{
Abbreviations: AL, antennal lobe; LFP, local field potential; LN, local interneuron of the antennal lobe; MGC, macroglomerular complex; $\mathrm{OB}$, olfactory bulb; ORN, olfactory receptor neuron; $\mathrm{PN}$, projection interneuron; PTX, picrotoxin; T1 to T6, tract 1 to tract 6 of the antennal nerve; TTX, tetrodotoxin; VSD, voltage-sensitive dye.

* Corresponding author. Tel.: +49-30-838-56454; fax: +49-30838-55455.

E-mail address: galizia@zedat.fu-berlin.de (C.G. Galizia).
}

number is probably well below 100 (Clyne et al., 1999; Rubin et al., 2000; Vosshall et al., 1999).

A striking similarity across animal phyla is the glomerular organization of the primary neuropil of the olfactory system, be it the olfactory bulb (OB) of vertebrates or the antennal lobe (AL) in insects (Strausfeld and Hildebrand, 1999). This unique structural principle could reflect a basic property of olfactory coding because there might be no set of physical properties (such as wavelength for light or pitch for sound) common to all odours that can be mapped in a small number of dimensions, and therefore there is no organizing principle suitable for a functional architecture (but see Turin, 1996, for a different view). Rather, olfaction appears to be intrinsically multidimensional, and a glomerular morphology may be a structural organization that helps to convert a multidimensional set of inputs into a spatial activity map at the first level of sensory processing. This would imply that such a spatial organization is a convenient 'design' for processing multidimensional information. In olfactory coding different multidimensional spaces are realized. In a simplified scheme, four such spaces can be 
defined: first, the 'external' multidimensional stimulus space, i.e. the odour world, which has axes defined by the chemical and physical properties of the odorant molecules. Some of these axes are easy to define, such as carbon chain length for simple hydrocarbons or electronegativity for functional group residues. Molecular resonance frequencies, which are exploited in spectroscopic analysis, also define a classification system (Turin, 1996). However, any organization of molecules in a multidimensional space is a matter of definition, rather than a natural order. The second is a biologically defined input space, where each dimension is defined by the response properties of olfactory receptor neurons (ORNs). Its organization depends on the receptor genes expressed, and is thus different in different species. The mapping of the physico-chemical space onto the receptive space is the first step in olfactory coding; it can, of course, be subdivided into finer steps, these being the interactions with olfactory binding proteins, the olfactory receptor proteins, transduction and second messenger pathways. The third space consists of the glomerular activity patterns in the AL or OB. This space represents a transformation of the second one, where the neural network of the AL or the $\mathrm{OB}$ accomplishes the transformation. It should be noted that 'glomerular activity pattern' is a descriptive term with fuzzy boundaries, since it is sometimes used for the activity of the ORNs alone, sometimes for the output from the glomeruli, and sometimes for a compound activity of all cells involved. In the fourth and biologically most relevant space, odours are arranged according to their perceptual similarity, i.e. odours that are perceived as being similar are close in the perceptual odour space. In order to experimentally map the position of odours in such a space, and to get a measure of the dimensionality of it, large matrices of mutual odour similarity must be produced and processed with multivariate statistical tools (Schiffman, 1981). Established experimental procedures to behaviourally measure odour similarity can be used for this purpose (Laska et al., 1999a; Laska and Freyer, 1997; Laska and Teubner 1998, 1999).

In mammals, the axons of ORNs project in an orderly and highly specific pattern into the primary sensory neuropil, the OB (Mombaerts et al., 1996; Wang et al., 1998). Here, ORNs that express the same receptor gene all project into the same glomerulus of each half-OB (Mombaerts, 1996). The expressed receptor gene influences the position of the target glomerulus (Mombaerts et al., 1996; Wang et al., 1998), but it is unknown whether additional rules define the arrangements of the glomeruli into a functional map of odour representation. In the vomeronasal organ ORNs expressing a particular receptor gene innervate more than one glomerulus (Belluscio et al., 1999; Rodriguez et al., 1999).

In insects, the rules governing receptor innervation of ordinary glomeruli are unknown. The receptor gene fam- ily of Drosophila, which was first estimated at more than 100 genes (Clyne et al., 1999; Vosshall et al., 1999), is now believed to consist of 57 genes (Rubin et al., 2000). This compares to about 43 glomeruli (Laissue et al., 1999), which presents the possibility that some glomeruli are innervated by more than one type of ORN. Furthermore, on the maxillary palp there are six physiological response types of ORNs, housed as three stereotyped pairs in the sensilla (de Bruyne et al., 1999). If these innervate only three glomeruli of the AL (Stocker, 1994), that would suggest a numerical relationship of $2: 1$; however, the glomeruli innervated by receptors from the maxillary palp may also be five (Singh and Nayak, 1985).

In order to understand the olfactory code, it is necessary to understand the rules of glomerular organization both at the neuroanatomical and functional level. Neuroanatomical data based on the selective staining of receptor molecule expression in ORNs are being accumulated for the mammalian system (Bulfone et al., 1998; Mombaerts et al., 1996; Tsuboi et al., 1999; Wang et al., 1998), and will soon also be available for insects (Clyne et al., 1999; Vosshall et al., 1999). However, tracing studies and single cell markings still provide the main basis upon which neuroanatomical data are based in insects. For example, in the macroglomerular complex (MGC) of the heliothine moth Heliothis virescens, the glomerular projection patterns and physiological response profiles of both ORNs and projection neurons (PNs) have been mapped (Berg et al., 1998; Vickers et al., 1998). Functional studies of odour-induced activity patterns in the $\mathrm{OB}$ and AL have recently added insight into the organization of the first olfactory neuropil (see Table 1).

\section{Optical imaging of glomerular activities}

Several experiments have shown that stimulating with odours leads to spatially organized activity patterns in the $\mathrm{AL}$ and the $\mathrm{OB}$. Measurements using radioactively marked 2-deoxyglucose (2DG) reveal such patterns in the OB of mammals (Coopersmith and Leon, 1984; Johnson et al. 1998, 1999; Johnson and Leon, 1996; Jourdan et al., 1980; Lancet et al., 1982; Sharp et al., 1975; Stewart et al., 1979; Teicher et al., 1980) and within insects in Drosophila (Rodrigues, 1988; Rodrigues and Buchner, 1984) and Calliphora vicina (Distler et al., 1998). These measurements show that, in response to an odorant stimulus, activity is focused in discrete glomeruli of the OB or the AL. Each odour elicits a mosaic of activated glomeruli, a finding confirmed by mapping odour-evoked neural activity monitoring c-fos expression (Guthrie et al., 1993; Guthrie and Gall, 1995; Johnson et al., 1995; Sallaz and Jourdan 1993, 1996). Unfortunately, for these measurements each animal has 
Table 1

Summary of imaging studies of the olfactory bulb or the antennal lobe, in which spatial activity patterns of glomeruli were recorded as responses to olfactory stimuli

\begin{tabular}{|c|c|c|c|c|c|c|c|c|}
\hline Species & Dye & Structure & $\begin{array}{l}\text { Temporal } \\
\text { resolution }\end{array}$ & Averaging & $\begin{array}{l}\text { Spatial } \\
\text { resolution } \\
(\mu \mathrm{m})\end{array}$ & $\begin{array}{l}\text { Size of } \\
\text { glomeruli } \\
(\mu \mathrm{m})\end{array}$ & $\begin{array}{l}\text { Glomeruli } \\
\text { identifiable }\end{array}$ & References $^{\mathrm{a}}$ \\
\hline $\begin{array}{l}\text { Honeybee: Apis } \\
\text { mellifera }\end{array}$ & Ca-green AM & Neuropil & $2-3 \mathrm{~Hz}$ & no & 5 & $20-50$ & yes & $(1),(2)$ \\
\hline $\begin{array}{l}\text { Honeybee: Apis } \\
\text { mellifera }\end{array}$ & Ca-green AM & Neuropil & $2-3 \mathrm{~Hz}$ & no & 5 & $20-50$ & no & $(3),(4),(5)$ \\
\hline $\begin{array}{l}\text { Honeybee: Apis } \\
\text { mellifera }\end{array}$ & RH 795 & Neuropil & $3 \mathrm{~Hz}$ & $8-16$ & 5 & $20-50$ & no & $(4),(6)$ \\
\hline $\begin{array}{l}\text { Carpenter ant: } \\
\text { Camponotus rufipes }\end{array}$ & Ca-green AM & Neuropil & $2 \mathrm{~Hz}$ & no & 5 & $10-30$ & no & (7) \\
\hline $\begin{array}{l}\text { Zebrafish: Danio } \\
\text { rerio }\end{array}$ & Ca-green-dextran & ORN terminals & $2-3.5 \mathrm{~Hz}$ & no & $3^{\mathrm{b}}$ & $8-20^{c}$ & no & (8) \\
\hline $\begin{array}{l}\text { Zebrafish: Danio } \\
\text { rerio }\end{array}$ & Di8-ANEPPQ & $\begin{array}{l}\text { ORN terminals and } \\
\text { axons }\end{array}$ & $20-40 \mathrm{~Hz}$ & $6-14$ & $3^{\mathrm{d}}$ & $8-20$ & yes/no ${ }^{e}$ & (9) \\
\hline $\begin{array}{l}\text { Salamander: } \\
\text { Ambystoma } \\
\text { tigrinum }\end{array}$ & RH414 & Neural tissue & $30 \mathrm{~Hz}^{\mathrm{f}}$ & $1-4$ & $20^{\mathrm{g}}$ & $30-120^{g}$ & no & $(10)$ \\
\hline $\begin{array}{l}\text { Rat: Rattus } \\
\text { norvegicus }\end{array}$ & $\begin{array}{l}\text { Intrinsic } \\
\text { (hemoglobin) }\end{array}$ & Neural tissue & $10 \mathrm{~s}^{\mathrm{h}}$ & $6-12$ & $4.95-6.41$ & 150 & no & (11) \\
\hline
\end{tabular}

a (1) Sachse et al., 1999; (2) Galizia et al., 1999a; (3) Joerges et al., 1997; (4) Galizia et al., 1997; (5) Galizia et al., 1998. (6) Galizia et al., 2000; (7) Galizia et al., 1999c; (8) Friedrich and Korsching, 1997; (9) Friedrich and Korsching, 1998; (10) Cinelli et al., 1995; (11) Rubin and Katz, 1999.

${ }^{\mathrm{b}}$ Images were taken with the $20 \times$ objective, and $128 \times 128$ or $170 \times 170$ resolution. Assuming a field of view of about $460 \mu \mathrm{m} \times 460 \mu \mathrm{m}$, this gives a spatial resolution or $2.5-3.5 \mu \mathrm{m}$. In some cases, the $40 \times$ objective was used, giving a spatial resolution of $1.3-2 \mu \mathrm{m}$. $1.33 \mu \mathrm{m}$ in Fig. $2 \mathrm{C}$.

${ }^{c}$ From Fig. 2C, Fig. 3C (8). Signals were prominent in the 'lateral chain', which is not as clearly parcellated into glomeruli as many other regions of the OB. The authors therefore refer to 'glomerular modules'

${ }^{\mathrm{d}}$ Resolution differed in individual measurements between 1.33 and $10 \mu \mathrm{m}$.

e In this study, some glomeruli were clearly identifiable on the basis of their responses.

${ }^{\mathrm{f}}$ Sometimes $60 \mathrm{~Hz}$ were achieved.

g J. Kauer, personal communication.

${ }^{\mathrm{h}}$ Images were acquired at video rate, but analysed in 10-s blocks.

to be killed after a single and long-lasting stimulation, and therefore only one map of a chronic sensory stimulation can be created from each individual, thus losing temporal information and precluding within-animal comparisons.

Optical recording techniques have been developed to overcome these problems. Changes of intrinsic signals, due to different oxygenation levels of haemoglobin in active and non-active brain regions, were used in the rat OB (Rubin and Katz, 1999). Intrinsic signals were also measured in honeybee AL (Lieke, 1993). Voltage-sensitive dyes (VSDs) have given good results in salamanders (Cinelli et al., 1995; Kauer et al., 1987; Kauer, 1991), zebrafish (Friedrich and Korsching, 1998), frogs (Shah et al., 1999), turtles (Lam et al., 2000) and molluscs (Kleinfeld et al., 1994). In some of these studies the signals were not related to the glomerular units (Delaney et al., 1994; Gelperin et al., 1996; Gervais et al., 1996; Lieke, 1993; Shah et al., 1999). In honeybees, staining with VSDs allows the glomerular layout to be recognized very clearly in the staining pattern (Galizia et al. 1997, 2000); this shows that the activity patterns are indeed of glomerular origin, i.e. that the boundaries of highly active regions coincide with the boundaries of individual glomeruli (Fig. 1).

Changes in intracellular calcium concentrations have also been monitored successfully. The spatial distribution of receptor cell activity in the OB of the zebrafish was visualized by bulk staining the afferent receptor axons with calcium green (Friedrich and Korsching, 1997). Using a different staining protocol and the honeybee as experimental species, we were able to use changes in intracellular calcium concentration to measure glomerular activity patterns (Faber et al., 1999; Galizia et al. 1997, 1998; Galizia et al., 1999a; Joerges et al., 1997; Sachse et al., 1999). In these experiments, we bathapplied calcium green-AM (which is the calcium-sensitive dye calcium green covalently bound to an acetoxymethyl group). This cell-permeant molecule is inefficient as a calcium indicator in its AM-bound form and is taken up by all cells in the AL; however, inside the cells esterases cleave the AM group, leaving the now active and cell-impermeant calcium green captured within the cell. Therefore, in these experiments a compound signal of the activity of afferent receptor cells (ORNs), local inter- 

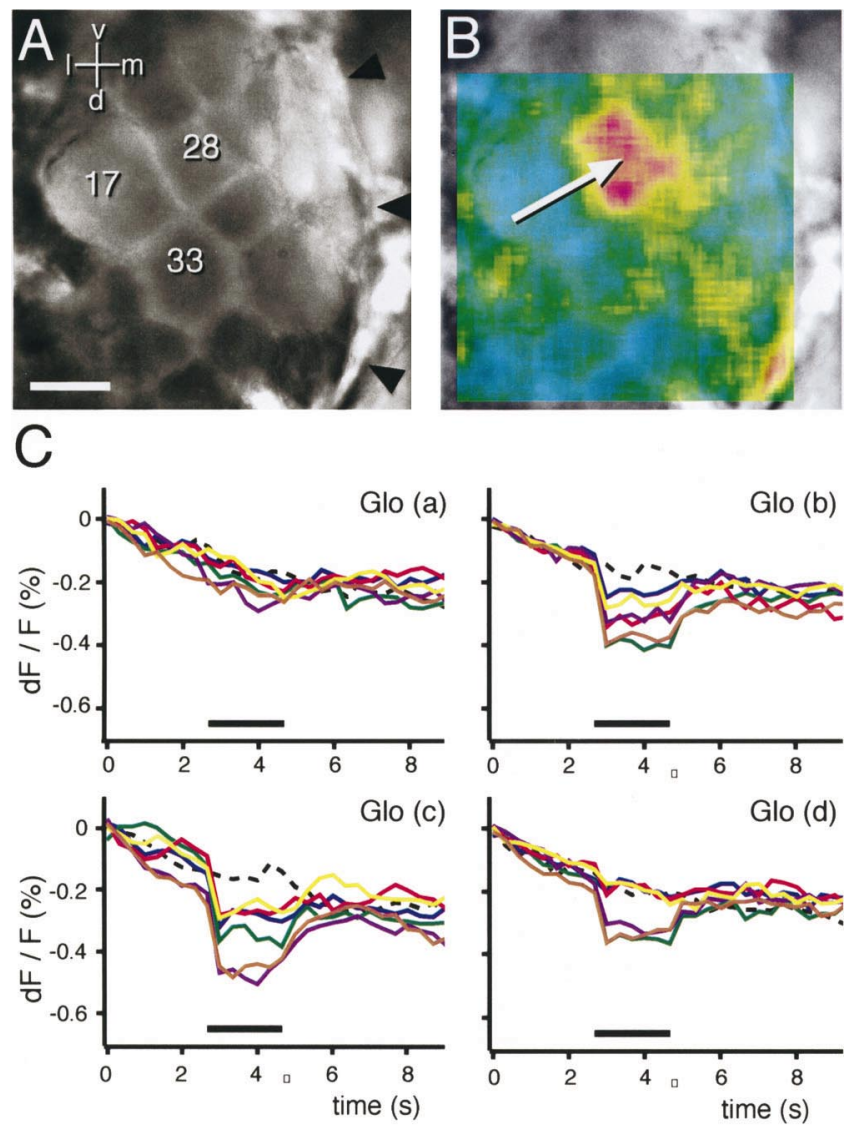

citral

clove oil

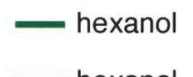

\section{hexanol+citral}

_ hexanol+hexanal

.. air control

Fig. 1. Imaging voltage-sensitive dyes in the AL of the honeybee. Optical recording of odour-evoked responses in the antennal lobe of the honeybee using voltage-sensitive dyes. (A) Staining with the RH795 dye gives a clear view of the glomerular structure of the AL. Scale bar is 50 $\mu \mathrm{m}$. Arrowheads indicate the limits of the AL. d, dorsal; v, ventral; 1, lateral; m, medial. Three glomeruli are marked with their identity: '28' (T1-28), '17' (T1-17), '33' (T1-33). (B) Same view as in A, but with a superimposed false colour-coded activity map of the response to hexanal. Red indicates strong membrane depolarization; blue indicates no change in membrane potential. Only part of the view field has been activitymeasured in this experiment. The glomerulus with the strongest response is marked with an arrow. This is glomerulus T1-28, which is the glomerulus which also shows the strongest response to hexanal in calcium imaging (Fig. 3). A and B adapted from Galizia et al. (1997). (C) Examples of response curves to odours and binary mixtures for four glomeruli in a single individual. Different individual from $\mathrm{A}$ and $\mathrm{B}$. The curves show the changes in relative fluorescence $(\Delta F / F)$ in \% over time (s) in an average of eight consecutive stimulations. The bar indicates the odour stimulus (2 s). Fluorescence decreases continually due to dye bleaching. Membrane depolarization leads to reduced fluorescence (the curve drops). Note that different glomeruli show different response properties in terms of both single-odour response and odorant mixtures. (a) No response to any of the tested odours. (b) Response to all odours; strongest response to hexanol (green curve). Odorant mixtures give a response equal to that of the largest component. (c) Responses to mixtures correspond to the sum of the components (purple and brown curve). (d) Glomerulus selective to hexanol (green curve), with no response to the other odours tested, responds to both binary mixtures containing hexanol with the same response as to the single component. Adapted from Galizia et al. (2000). neurons (LNs), projection interneurons (PNs) and possibly glial cells was measured.

This review focuses on optical imaging studies where 'general' odours (as opposed to sexual pheromones) were used as stimuli. Studies where electrical stimulations were used to analyse the olfactory pathway are not included. Table 1 gives a summary of studies published so far, in which odour-evoked activity patterns could be related to glomeruli. The main results from these studies are the following (see also the figures with examples from the honeybee, Apis mellifera):

1. Each odour evokes activity in several glomeruli, and each glomerulus participates in the evoked pattern of several odours. Different odours elicit different patterns (Figs. 1 and 2). This observation is common to all studies in Table 1, irrespective of the species used, and confirms several studies which mapped odour responses using radioactive markers (see above). The variability between repeated odour stimuli is low (Galizia et al., 1998). This confirms that odours are coded in an 'across-glomeruli' pattern, as has long been shown on the basis of several studies in various species (Hildebrand and Shepherd, 1997; Mori et al., 1999). The 'across-glomeruli' pattern in the $\mathrm{AL}$ or the bulb is probably translated into an 'across-fibre' pattern in the PNs or mitral/tufted cells. The 'read-out system', i.e. higher-order brain centres, must have access to the whole pattern, because the individual glomeruli are not sufficient for odour identification (but see below for a discussion of the redundancy in this code).

2. The response intensity is graded (Figs. 1, 3 and 4), both for the same odour, where stimulus concentration is reflected in stronger excitation, and for different odours, where one glomerulus with a weak response for one odour may well give a strong response to stimulation with another odour (Cinelli et al., 1995; Friedrich and Korsching, 1997; Joerges et al., 1997; Rubin and Katz, 1999).

3. The responses to mixtures indicate interglomerular computation. The response to binary mixtures approximates the additive combination of the components' responses (Joerges et al., 1997; Rappert et al., 1998) (Fig. 2C). However, slight deviations both in positive and negative directions appear. If mixtures of odours were represented as a simple addition of the activity patterns induced by the components, the glomerular code could saturate quickly, and mixtures would not be discriminated. Interactions, particularly of an inhibitory kind, between the glomeruli within the AL are therefore necessary and are likely to be important steps in olfactory information processing. Indeed, when increasing the components in the mixture blend, the inhibitory interactions appear to increase, thus pro- 

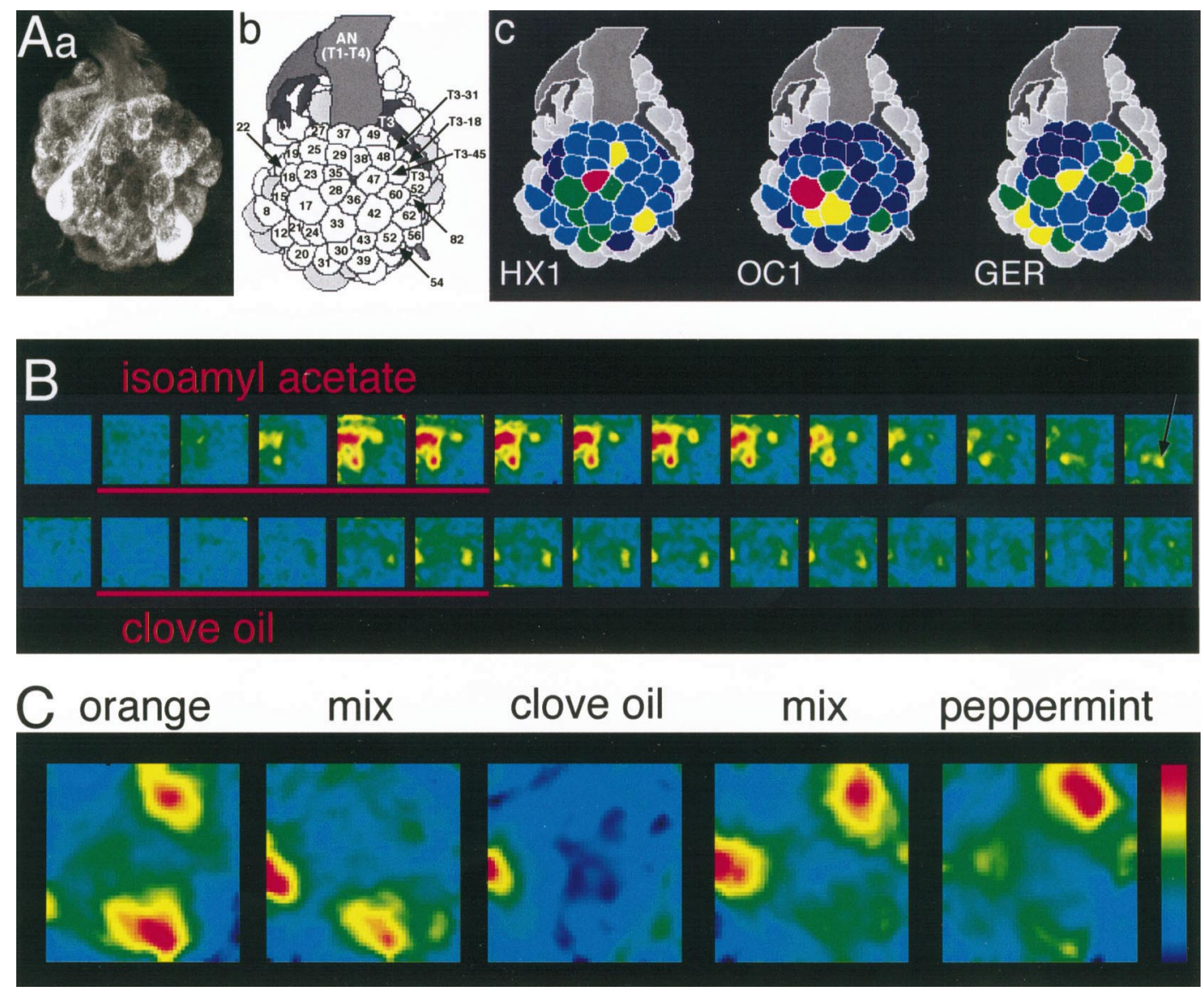

Fig. 2. Calcium imaging of odour-evoked activity in the honeybee AL. Optical recording of odour-evoked responses in the antennal lobe of the honeybee using calcium-sensitive dyes. (A) (a) Confocal reconstruction of the AL, obtained as extended focus of confocal sections from a preparation where receptor cell axons have been fluorescently labelled. The antennal nerve points up. (b) schematic view of the AL, with those glomeruli labelled which have so far been identified in optical imaging studies of odour-evoked activity. (c) False-colour-coded response patterns as obtained from averaging the responses in several animals, and displayed using a schematic view of the AL. Responses to 1-hexanol (HX1, $n=21$ ), 1-octanol $(\mathrm{OC} 1, n=21)$ and geraniol (GER, $n=9)$. Response strength is coded in five steps (red-yellow-green-blue-dark blue, see bar in Fig. 4); grey glomeruli could not be physiologically mapped. The spatial patterns of the perceptually more similar odours octanol and hexanol have more of the activity pattern in common with each other than either does with geraniol, though there is some overlap between the three. Based on data from Galizia et al. (1999a), compare with Fig. 4. (B) Temporal sequence of activity. Two frames per second, with the red bar giving the stimulus period. Both sequences are shown with the false-colour map scaled to the same range. Note the strong and spatially more widespread response to isoamyl acetate, and the later and weaker response to clove oil, which is limited to two non-contiguous glomeruli, one to the middle of the left margin, one to the middle of the right margin of the field of view. Also note that the response to isoamyl acetate is temporally complex: the pattern still active at the end of the sequence is not identical to the initial activity pattern, and includes an additional glomerulus (arrow). (C) Mixture interactions show additive and inhibitory effects. Responses to orange, clove oil and peppermint are shown with the responses to two of their binary mixtures in between them. Note that the response pattern to clove oil+peppermint corresponds to the sum of the components, whereas the response to orange+clove oil lacks the upper glomerulus which is part of the response to orange. Far right: sequence of colours for B and C.

ducing blend-specific excitation patterns (Joerges et al., 1997).

4. The representation of odours is symmetrical in the right and the left $A L$. This has been shown in honeybees by statistically comparing the response variability for repeated stimulation in one AL with the variability between right and left AL (Galizia et al., 1998). Therefore, rules leading to the functional identity of a glomerulus in development are equal on the two body sides, suggesting that these rules are genetically encoded.

5. Patterns are equal between individuals, which means that the code is conserved within a species.
This was reported for patterns in zebrafish (Friedrich and Korsching, 1998), salamander (Cinelli et al., 1995) and rat (Rubin and Katz, 1999), and confirms earlier 2DG data from rat (Johnson et al., 1998). However, a similar pattern does not unambiguously prove that homologous glomeruli are involved. Therefore, it is necessary to morphologically identify the glomeruli that are physiologically characterized. So far, this has been achieved in two species, the zebrafish and the honeybee. In the zebrafish, a single, highly specific glomerulus selectively responding to a putative pheromone was found in which both anatomical shape and physiological 


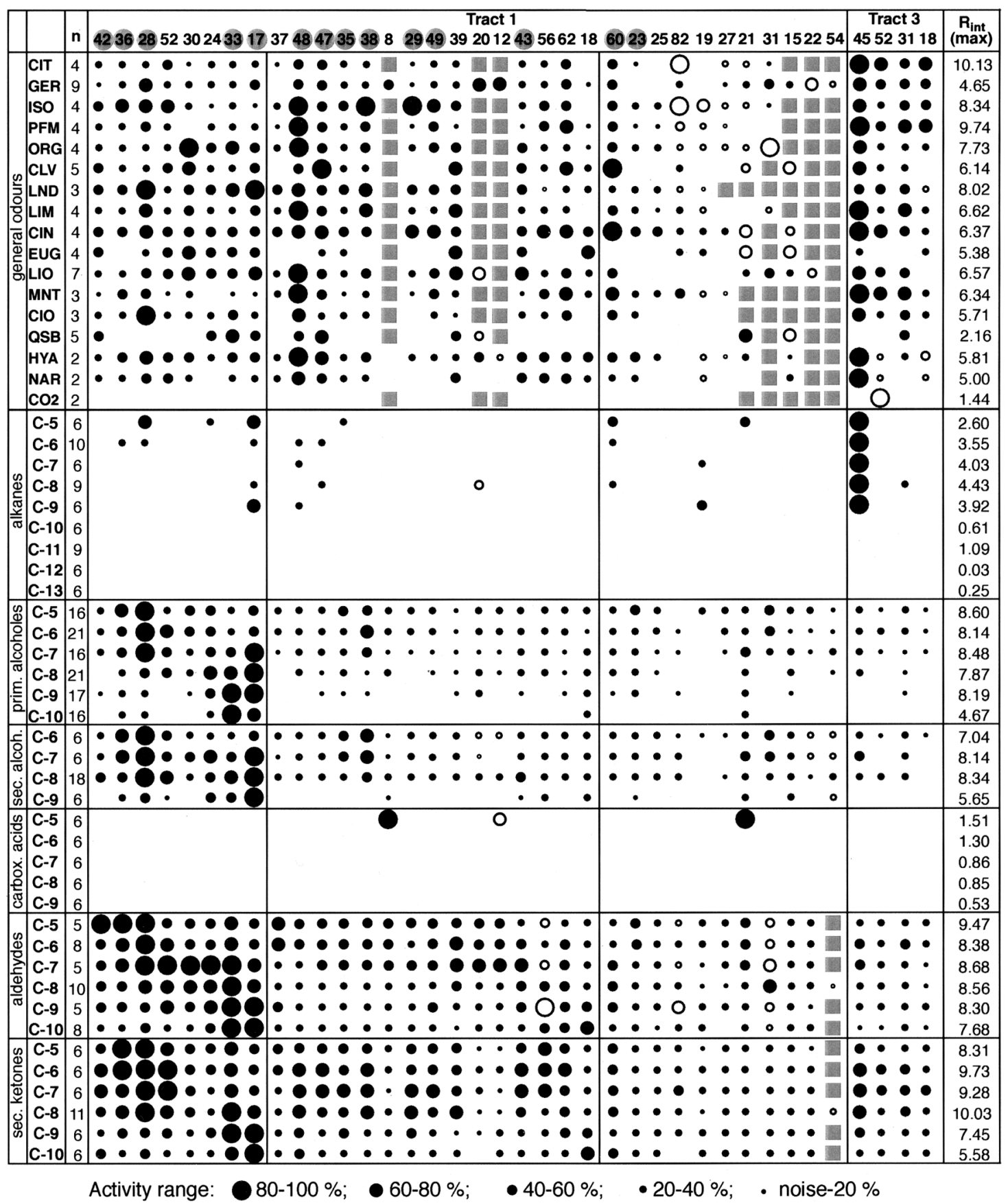

Fig. 3. Glomerular representation of odours in the antennal lobe. Response patterns to 53 different odours obtained by averaging the responses in morphologically identified glomeruli from several animals, adapted from Galizia et al. (1999a) and Sachse et al. (1999). Each row represents an odour, each column an identified glomerulus. Response strength is displayed as circle size in 5 bins (see legend), and normalized within each row (the maximal response is given in the right column, $R_{\mathrm{int}}(\max )$ ). $n$ gives the number of animals averaged in each row. Glomeruli marked with a circle in the top row were identified in all animals - the other glomeruli are only sampled in a subpopulation; a grey box indicates where a glomerulus could not be identified in any of the tested animals; an empty circle indicates results from a single animal (no average). Empty spots indicate a calcium response below noise level. Note the distributed nature of the activity patterns for all odours. Glomeruli have been sorted by functional aspects: note the systematic shift of the strong activity in the first group of glomeruli to hydrocarbons of increasing chain length, and also in the second group, where activity to hydrocarbons was less pronounced, but still shifted systematically. For all hydrocarbons (secondary ketones, aldehydes, carboxylic acids, secondary alcohols, primary alcohols, alkanes), only the chain length is given within each group for simplicity. The code for the other odours ('general odours') is: CIT, citral; GER, geraniol; ISO, isoamyl acetate; PFM, peppermint oil; ORG, orange oil; CLV, clove oil; LND, lime-blossom (Tilia); LIM, limonene; CIN, cineol; EUG, eugenol; LIO, (+)-linalool; MNT, (-)-menthol; diluted in $n$-hexane; CIO, DL-citronellol; QSB (queen substance), synthetic queen bee mandibular complex; HYA, headspace of hyacinth flower, dissolved in $n$-hexane; NAR, headspace of narcissus flower, dissolved in $n$-hexane; $\mathrm{CO} 2$, carbon dioxide. CIT, GER, ISO are pheromone components, but also plant substances; QSB is the sexual pheromone of bees. 


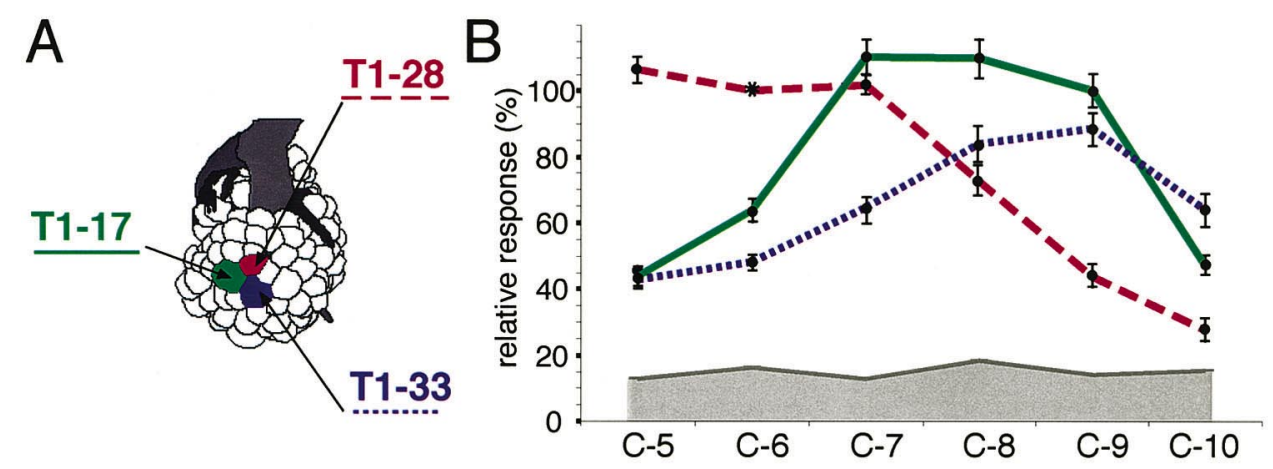

C
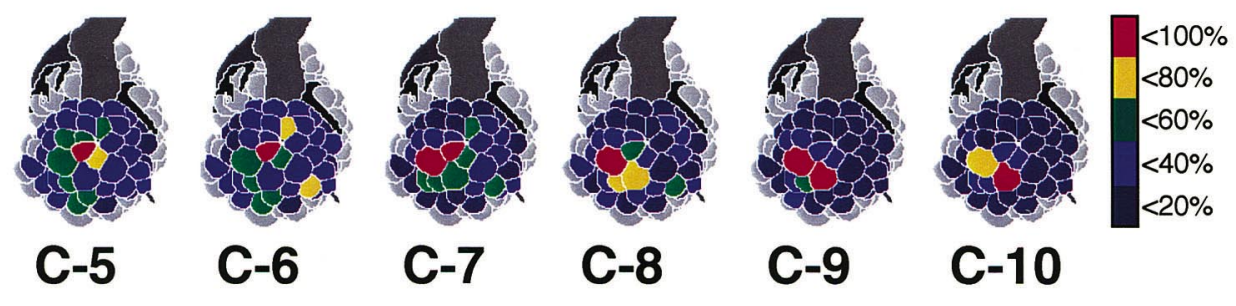

Fig. 4. Increasing alcohol chain length leads to a shift of the activity pattern. (A) Schematic view of the honeybee AL. The names of three glomeruli are given (T1-17, T1-28, T1-33). (B) Response curves of the three glomeruli given in A to a series of homologous alcohols from C5 (1-pentanol) to $\mathrm{C} 10$ (1-decanol). Response to hexanol in T1-28 is set to $100 \%$ for standardization (asterisk). Note that each glomerulus has a broad response profile. (C) Spatial patterns of the responses to a homologous series of aliphatic alcohols from C5 (1-pentanol) to C10 (1-decanol). Averaged data, false-colour coded on a schematic view of the honeybee AL. Response strength is coded in five steps (red-yellow-green-bluedark blue, see colour bar at right), grey glomeruli could not be physiologically mapped. The strongest response to 1-decanol is in T1-33, with a weaker response in T1-17. As the carbon chain shortens, activity shifts along the series T1-33, T1-17, and T1-28. Note that here six chemical substances which can be ordered on the basis of their physical properties are processed in a series of three glomeruli, i.e. only half as many. However, the spatial representation of aliphatic alcohols is not limited to these three glomeruli, because other glomeruli also respond to these stimuli. Adapted from Galizia and Menzel (2000) and Sachse et al. (1999).

responses were equal between individuals (Friedrich and Korsching, 1998). In honeybees, glomeruli can be morphologically identified using a three-dimensional, digital atlas of the AL (Galizia et al., 1999b). This is possible because in many insects individual glomeruli have characteristic shapes, sizes and relative positions, thus making them readily identifiable (Flanagan and Mercer, 1989a; Laissue et al., 1999; Rospars, 1988; Rospars and Hildebrand, 1992). In this way, glomerular identification was based on independent data from their physiological response profile. We showed that responses are equal within the species at the level of identified glomeruli; it was possible to predict, from the observed glomerular activity patterns, the odour which elicited the pattern with an accuracy of over $85 \%$ (Galizia et al., 1999a). This extends the finding of bilateral symmetry and corroborates the interpretation that the physiological identity of individual glomeruli may be genetically determined. Homologous glomeruli in different individuals have the same molecular response profile, and by measuring such profiles it is possible to create a functional atlas of odour representations in the $\mathrm{AL}$ of honeybees (Fig. 3). Nevertheless, there is also variability between individuals, indicating that not all is hardwired in the AL. Indeed, learning can influence odour representation in the AL (see point 10, below).

6. Responses to hydrocarbons are broadly tuned with respect to carbon chain length (Fig. 4). In honeybees, a glomerulus that preferentially responds to a particular hydrocarbon, say 1-octanol, will always also respond to its carbon chain-length neighbours, in this case 1-heptanol and 1-nonanol, though with less intensity (Sachse et al., 1999). Similarly, in rats, glomeruli responding to a homologous series of aliphatic aldehydes almost always responded to consecutive members of the series (Rubin and Katz, 1999). This reflects the broad tuning of receptor cells (Mori, 1995). A corollary is that activity maps elicited by consecutive members of homologous hydrocarbon series (e.g. hexanol and heptanol) should be more similar than maps from distant members (e.g. hexanol and decanol). This is indeed the case (Rubin and Katz, 1999; Sachse et al., 1999). In this respect it is interesting to note that when honeybees are behaviourally tested with homologous series of hydrocarbons, the only mistakes in odour choice occur between direct neighbours in terms of carbon chain length (Laska et al., 1999a). A correlation between carbon chain length similarity and perceptual similarity was also found in monkeys and 
humans (Laska et al., 1999b; Laska and Freyer, 1997; Laska and Teubner 1998, 1999). This indicates that the transformation from the multidimensional odour space in the antennal lobe to the perceptive space may keep the topology intact, at least for aliphatic hydrocarbons.

Note, however, that at least some receptor cells are not broadly tuned, but respond with high selectivity to only a few compounds if stimulated with biologically relevant volatiles at low concentrations, as demonstrated by linked gas chromatographyelectrophysiology (Blight et al., 1995; de Bruyne et al., 1999; Imamura et al., 1992; Malnic et al., 1999; Røstelien et al., 2000; Tømmerås and Mustaparta, 1987). Future research will have to evaluate the neural strategies underlying processing of highly specific and more general chemosensory input.

7. In honeybees, there may not be particular glomeruli for functional groups (Sachse et al., 1999). When tested for different functional groups (aldehydes, ketones, alcohols, carbon acids and alkanes), glomeruli preferentially responded to one functional group rather than to another. However, these glomeruli always also responded to other functional groups, even though that response was weaker. Furthermore, they always had a particular preferred range of carbon chain lengths to which they responded. Therefore, the response profile of individual glomeruli is not determined by functional groups, such as 'ketone group' or 'aldehyde group', and the olfactory code is not a building set, where 1-heptanol would be coded in the 'alcohol glomerulus' plus the ' $\mathrm{C} 7$ aliphatic chain glomerulus'. Rather, response profiles are best described as broadly tuned to the whole 'best molecule': for example, glomerulus T1-17 best responds to 1-heptanol, but is also activated by other alcohols with similar carbon chain length, as well as ketones and aldehydes of the same carbon chain-length range (Figs. 3 and 4B). This shows the importance of an across-glomeruli code: from the activity of T1-17 alone, it is not possible to distinguish a weak stimulation with 1-heptanol from a strong stimulation with heptanone. By means of a comparison with the other glomeruli this identification is, however, unambiguous.

This is in contrast to what has been proposed for rats (Johnson et al., 1998), where 2DG measurements suggest that the identity of the odorant may be determined by a simultaneous decoding of the combination of molecular features represented in the glomerular layer. These features have been called odotopes (Shepherd, 1987). No imaging data of different functional groups are available from rats so far.

8. The spatial arrangement of glomeruli is related to their response profile for some glomeruli. When zebrafish are stimulated with different amino acids, the response patterns in the $\mathrm{OB}$ cluster into four groups for amino acids with common molecular features: basic, acidic, neutral with short aliphatic residues and neutral with long non-polar residues (Friedrich and Korsching, 1997). This clustering was confirmed using factor analysis, showing that ORNs with similar response properties tend to innervate adjoining regions of the bulb. In honeybees, glomerulus T1-17 preferentially responds to 1-heptanol (Fig. 4). Its direct neighbours, T1-28 and T1-33, preferentially respond to 1-pentanol and 1-nonanol, respectively (Sachse et al., 1999). In mammals, close mitral cells have similar response profiles (Mori et al., 1992). In rats, using a homologous series of aliphatic carbon acids as stimuli, a similar shift was found using 2DG (Johnson et al., 1999). This has not yet been confirmed in imaging studies (Rubin and Katz, 1999), possibly because the relevant part of the OB was not within the area that was imaged. Close neighbourhood may reflect an optimal spatial arrangement for a lateral inhibition mechanism to sharpen broadly tuned response profiles, which would result in a sharper tuning of the responses in PNs. Such a mechanism has been shown in rabbit mitral cells (Katoh et al., 1993; Yokoi et al., 1995). However, this is not a general rule. The odour-specific glomerular activity patterns are generally distributed, i.e. in most response patterns there are several activated glomeruli which are not direct neighbours, as can be seen in almost any spatial activity map from the references listed in Table 1 . In insects, LNs interconnect glomeruli from wide areas of the AL; therefore, physically distant glomeruli may also be physiological neighbours.

9. The olfactory code is redundant. Rats have been shown to be able to recognize odours with only $21 \%$ of their OB left after partial bulbectomy, even if the regions removed included areas that were shown to be activated in 2DG studies (Lu and Slotnick, 1998; Slotnick et al., 1987). Therefore, it is not necessary to have the entire representation (i.e. the entire OB) for correct odour identification. To what extent this feature is used in the intact animal is unknown. It might be that the entire representation is commonly used, and the redundancy helps to reduce errors. In honeybees, after mapping the response properties of a mere subpopulation of morphologically identified glomeruli (24\%), we found that this subset was sufficient to unambiguously predict the odour from the pattern (Galizia et al., 1999a). A discriminant analysis gave a rate of over $85 \%$ correctly predicted odours. This confirms that the information in the spatial pattern is redundant. It also shows that the spatial pattern is sufficient to encode the odour, 
though it does not prove that the animal makes use of it.

10. In honeybees, associative learning of odours leads to changes in the glomerular activity pattern for the learned odour. Activity patterns evoked by two odours were measured in the naive bee, and then one odour was trained in an appetitive classical conditioning paradigm, while the other was presented without reward. After this differential conditioning, the rewarded odour led to a response pattern with increased activity, and this pattern was less correlated with that of the non-rewarded odour than before training (Faber et al., 1999). Interestingly, in intracellular recordings of PNs, an increased frequency was found in the response to an odour after single-trial appetitive training (Abel, 1997). Thus, the across-glomerular and across-fibre code is not stereotypical, but plastic. The range of plasticity, however, appears to be rather narrow, because only subtle differences were found in both the glomeruli and PNs as a consequence of learning. Nevertheless, these findings show that within the stereotype species-specific glomerular code (see above, point 5), there is a plastic component. They corroborate the observation that the AL houses an olfactory memory trace, and this trace can control learned olfactory behaviour (Hammer and Menzel, 1998). It is yet unknown whether the olfactory memory in the AL develops under the feedback control of the MB, another site of olfactory memory (Menzel and Müller, 1996), and whether the contents of the memory traces in the AL and MB are different.

Developmental plasticity has also been shown for odour representation in the vertebrate bulb using 2DG staining. Early learning of an odour (peppermint from postnatal day 1 to 18 ) led to increased 2DG uptake and c-fos-expression in the posterior half of the midlateral portions of the $\mathrm{OB}$ (Johnson et al., 1995; Johnson and Leon, 1996). Interestingly, some areas responding to peppermint were not enhanced following the early learning procedure, suggesting that not the entire response pattern but a selected subpattern is affected. Furthermore, early learning also led to morphological changes, in that the plastic glomeruli increased in size (Woo et al., 1987). Morphological plasticity has also been shown in honeybee ALs: individually identified glomeruli change in relative size depending on the task of the worker bee in the hive (Sigg et al., 1997; Winnington et al., 1996).

11. The glomerular activity patterns are dynamic. Each odour does not only elicit a static pattern that is switched on or off depending on the presence of the odour. Rather, the representation of an odour is a spatio-temporal pattern (Fig. 2C). We found that the difference between the representations of two odours increased within the 2 s of stimulus presentation, which suggests that odour representations became more characteristic over time (Galizia et al., 2000). Thus, interglomerular connections sharpen the spatial response patterns. In optical recording studies of the OB with VSDs and higher temporal resolution, complex response patterns consisting of a brief, small hyperpolarization, followed by a period of depolarization, and then a longer-lasting hyperpolarization can be observed in salamander (Cinelli et al., 1995) but not in zebrafish (Friedrich and Korsching, 1998). Since in the experiments with zebrafish only the ORNs were stained, but in salamander all cells of the bulb contributed to the signal, these complex response patterns are likely to originate in the bulb network. Indeed, similar response patterns are reported for PNs in moths and salamander (Christensen et al. 1996, 1998; Hamilton and Kauer, 1989). The role of temporal patterns in odour responses is discussed below.

12. Non-sexual pheromones are coded as 'general' odours. This paper does not review the processing of sexual pheromones. However, pheromones also play a role in intraspecific communication that does not relate to mate finding. Non-sexual pheromones differ from sexual pheromones in that they are often less complex molecules, and may also be encountered as environmental odours. They often also act as kairomones_-such as alarm pheromones, which elicit alarm in several sympatric species (Hölldobler and Wilson, 1990). Important non-sexual pheromones for bees are: citral and geraniol, both components of the Nasanov-gland, which is important for the social cohesion of the hive (Free, 1987); isoamyl acetate, which is the major component of the alarm pheromone associated with the sting apparatus (Free, 1987; Nunez et al., 1997); and the repellent scentmarker 2-heptanone, which bees might use to mark already-visited feeding sites (Giurfa, 1993; Giurfa and Nunez, 1992). All of these substances have been tested in imaging studies. They elicit activity in the same region as environmental odours (Joerges et al., 1997; Galizia et al., 1999a; Sachse et al., 1999). Isoamyl acetate elicits strong responses in several glomeruli, including T1-48, a glomerulus that also exhibits strong responses to orange, clove-oil, limonene and several plant extracts (Fig. 3). It is unknown whether there is a parallel, more 'labelled line'-like pathway for these odours, reminiscent of the MGC system for sexual pheromones. If there is, this system is certainly not in the area of the AL whose response profiles have already been well-mapped, which is the T1 region (Sachse et al., 1999; Galizia et al., 1999a). It could be located in the T2, T3 or the T4 glomeruli, which have not yet been physiologically characterized (T1, T2, T3 and T4 glomeruli 
are those innervated by the antennal tracts $\mathrm{T} 1$ to $\mathrm{T} 4$, respectively. There are about 70 glomeruli each in the T1 and T3 groups, and 7 each in T2 and T4).

Ants also have a well-developed intraspecific communication system based on pheromones, which they use to communicate food-sources, trails, alarm, and so on (Hölldobler and Wilson, 1990). In the ALs of the ant Camponotus rufipes we compared activity elicited by environmental odours and by non-sexual pheromone substances, and were able to show that some glomeruli are activated by both substance groups, suggesting that-as in bees- the two systems overlap in this species (Galizia et al., 1999c).

\section{Unanswered questions when interpreting optical imaging data}

\subsection{Which components contribute to 'glomerular activity'?}

The glomerular activity pattern is at the interface between the primary biological olfactory space (defined by the ORNs) and the perceptive space. In order to understand the function of the $\mathrm{AL}$ or $\mathrm{OB}$ for the neural representation of odours, it would therefore be ideal toseparately-have access to the activity patterns of ORNs alone (as has been done in zebrafish (Friedrich and Korsching 1997, 1998) and to the output from the glomeruli (which was so far only successful for single-cell recordings, e.g. Yokoi et al., 1995; Christensen et al., 1996; Christensen and Hildebrand, 1987; Flanagan and Mercer, 1989b; Hamilton and Kauer, 1989; MacLeod and Laurent, 1996; Stopfer and Laurent, 1999; Sun et al., 1993). The transformation between the two is the result of the local network of the bulb or lobe. With exception of the zebrafish work, all imaging studies so far measured composite signals, where all cells participated in the activity patterns. These patterns therefore comprise input, processing activity, and output of the glomerular circuitry. How the compound activities relate to input and output depends on the neuronal wiring, on the relative contribution of the different compartments, and the sensitivity of the optical signal.

Focusing on neuronal wiring, let us consider the simplest case: each glomerulus would receive input from only one family of ORNs, and output neurons would be uniglomerular. In this case, the glomerular input would be an isomorphism of ORN families, and the glomerular output pattern would be an isomorphism of the acrossfibre pattern in the output neurons. If the network's task is to sharpen the glomerular odour representation, and to reduce noise by collecting signals from thousands of ORNs, then the output pattern should be very similar to the input pattern, but sharper, and lacking the weak glomeruli of the input. In this case, the measured activity maps would broadly mirror the ORN input. In the MGC of the heliothine moth Heliothis virescens, such a scenario appears to be realized: response profiles of ORNs to individual glomeruli match those of PNs (Berg et al., 1998; Vickers et al., 1998). However, this match between input and output is not found in other moth species (Anton and Hansson, 1999). Furthermore, since this is an example of a sex-pheromone coding system, it is unknown whether the same rules apply to general odour processing networks.

In insects it is possible that more than one ORN family innervates individual glomeruli (see Section 1). Furthermore, some of the PNs are multiglomerular. Therefore, the isomorphism to glomeruli is broken both on the input and the output side. In addition, LNs interconnect the glomeruli. How does a compound activity pattern comprising all AL cells compare to the output pattern? Glomeruli that are seen to be active in the compound signal may not excite their output neurons for two reasons. First, the glomerulus could receive ORN input (which would be the source the signal measured), but this activity would be inhibited along its way to the output neurons. Alternatively, a glomerulus, though not receiving ORN input, could be inhibited by local neurons, and the optical signal would monitor this input to the glomerulus from inhibitory cells. Consequently, an activated glomerulus in the compound signal does not guarantee excitation in its output. On the other hand, if the output of a glomerulus is active, there must be active synapses in that glomerulus to activate it, and thus other neurons active in that glomerulus. Therefore, it is unlikely that a glomerulus that appears silent in the compound signal contributes to the output pattern. Taken together, these signals may represent an overestimation of the output pattern in terms of participating glomeruli.

Another unanswered question relates to the calcium source in calcium imaging studies. How much of the observed calcium concentration increase is due to extracellular calcium, and how much comes from intracellular stores? This question has not been addressed so far.

\subsection{Subglomerular compartments}

What is the role of subglomerular compartments? In honeybees, the outer cap and the core of each glomerulus receive input from different neuron types. In most glomeruli, ORNs only innervate the outer cap (Arnold et al., 1985; Brockmann and Brückner, 1995). LNs innervate the entire glomerulus when they densely innervate it, but only the core of those glomeruli which they sparsely innervate (Abel, 1997; Fonta et al., 1993). Innervation by modulatory neurons is also selective: serotonergic neurons innervate only the cap (Schürmann and Klemm, 1984), octopaminergic neurons mainly the cap (Kreissl et al., 1994), and dopaminergic neurons only the core 
(Schürmann et al., 1989). Consequently, each glomerulus is concentrically organized into two subsets, and the cap may serve a different function than the core. In our imaging studies of the worker honeybee, temporal and spatial resolution were not sufficient to analyse a possible within-glomerulus organization of the activity signal. If the cap of a glomerulus-which is the target of the receptor cells-were active just a few milliseconds before the core, this could not be resolved with our temporal resolution of 300-500 ms. The limitation in spatial resolution of the glomerular substructure is mainly determined by the reduced focal discrimination, because for each pixel depicting part of a glomerulus, layers above and below the focal plane will add to the signal. This gives a signal that is the compound of the glomerular cap and the core. Thus, data with higher temporal and spatial resolution are necessary. The confocal microscope, or the two-photon approach, will be of particular help in studying the functional differences between cap and core.

Core and outer cap may not be the only subcompartments of a glomerulus. For example, in honeybees the spatial position of receptor cells along the antenna is also concentrically mapped within the outer cap (Boeckh et al., 1970; Pareto, 1972, C.G. Galizia, unpublished observations). Furthermore, within the glomerulus small modules are detectable, either as dense knots in morphological stainings of ORNs (C.G. Galizia, unpublished observations), or in immunostainings (U. Müller, personal communication). A subcompartmentalization of glomeruli has also been proposed for Drosophila (Halter et al., 1998). In locusts glomeruli are better described as microglomeruli, with ORNs and PNs often innervating non-adjoining groups of glomeruli (Anton and Hansson, 1996; Ernst et al., 1977). Possibly, glomeruli are not the smallest functional unit of the insect olfactory code.

\subsection{Temporal components of the olfactory code}

The dynamic aspects of the olfactory code are certainly among the most challenging ones. Not all glomeruli respond simultaneously at stimulus onset, but rather in a sequence, and the pattern at the end may be different from the initial one (see Fig. 2B). Therefore, odours do not just elicit a fixed pattern but rather a 'melody' of activated glomeruli.

Glomerular activity patterns evolve within $2 \mathrm{~s}$ after stimulus onset. This leads to a sharper representation of the odours, i.e. the differences in the representation of, say, hexanal and citral are greater $2 \mathrm{~s}$ after stimulus onset than right at the beginning of the stimulus (Galizia et al., 2000). Intracellular recordings from AL neurons have also indicated dynamic neural assemblies in the insect AL (Laurent, 1996), which evolve in the range of 2-3 s. However, odour recognition can also be much faster. In behavioural experiments, bees are able to recognize an odour within $0.5 \mathrm{~s}$ (J. Klein, personal communication), but it is not known whether discrimination improves for longer stimuli. Two seconds may be too long for some tasks that the animal has to perform in nature (e.g. in the honeybee discrimination of a hive mate from an intruder, detection of odours eddying from flowers at a distance). On the other hand, two seconds are usually well within the range of olfactory processing when it comes to the task of recognizing an odour and making a final decision close to the odour source. In contrast to floral odours, pheromones may require rapid processing. Moths flying upwind have been shown to respond behaviourally to single pheromone pulses of only a few tens of a millisecond duration (Kaissling, 1997). In moths, some PNs responding to pheromones can follow stimulus pulses up to $10 \mathrm{~Hz}$ (Christensen and Hildebrand 1988, 1997; Heinbockel et al., 1999; Lei and Hansson, 1999). The specialized MGC, where ORN responses and glomerular responses indicate a labelledline system of odour coding, may also have evolved by optimizing temporal resolution. Coding odours in labelled lines-as apparent for the coding of sexual pheromone substances-may allow for higher temporal resolution than across-glomeruli coding, because only hardwired and short-ranging inhibitory interactions between subcompartments of the AL are needed. Therefore, for the recognition of floral odours, and possibly also for non-sexual pheromones, more time may be necessary for a firm identification of the stimulus.

The precise timing of spikes relative to an oscillatory reference signal might be involved in odour coding (Laurent et al., 1996a; Wehr and Laurent, 1996). Oscillations in the olfactory system have been reported in a variety of animals (Delaney and Hall, 1996; Eckman and Freeman, 1990; Gelperin, 1994; Gelperin et al., 1996; Gervais et al., 1996; Heinbockel et al., 1998; Lam et al., 2000; Laurent et al., 1996b; Laurent and Davidowitz, 1994; Mellon and Wheeler, 1999; Tank et al., 1994). Possibly, they are necessary to coordinate the readout of spatially distributed neuronal populations. Alternatively, odours may be represented by a specific succession of synchronized assemblies (Laurent, 1996). The local field potential (LFP) oscillates at about $20 \mathrm{~Hz}$ upon stimulation with an odour in locusts (Laurent and Naraghi, 1994) and at $30 \mathrm{~Hz}$ in honeybees (Stopfer et al., 1997). In a combined behavioural-pharmacological approach Stopfer and co-workers proposed that the temporal component is not necessary for discriminating between dissimilar odours (geraniol vs. octanol or hexanol), whereas it may be necessary for odours which appear more similar to bees (octanol vs. hexanol, compare with the spatial patterns in Fig. 2A). Structurally and perceptually similar odours were less well discriminated after application of the ionotropic GABA receptor antagonist picrotoxin (PTX) (Stopfer et al., 1997). While PTX abolishes the oscillations in the AL, it may also affect the 
spatial representation of odours. Although Stopfer et al. did not find differences on the basis of the spike rate in PNs, we have recently seen effects of PTX on the glomerular activity patterns (A. Schlick, C.G. Galizia and S. Sachse, unpublished observations). The results from the PTX experiment can also be interpreted in terms of a spatial code hypothesis: two perceptually more similar odours may excite overlapping ORN populations. These project to different glomeruli, which are therefore also activated by both odours (though not necessarily to the same extent). This is particularly apparent with chemically related odours (Fig. 4). If the AL then sharpens the representation (Mori and Yoshihara, 1995) with the aid of interglomerular inhibition (Yokoi et al., 1995), this could be the mechanism-by itself independent of the oscillatory nature of the signal-being disrupted after PTX infusion. More experiments are needed to find out whether odours are coded in temporal or spatial patterns, or in a combination of the two. Ideally, such experiments would involve creating the percept of an odour by artificially eliciting the appropriate temporal (but not spatial) or spatial (but not temporal) pattern.

\section{Deciphering the code: what needs to be addressed next}

The optical imaging studies reviewed here pose new questions, and more research is needed to solve them. Of course, technical progress will improve the data: improving temporal resolution (mainly limited by the signal-to-noise ratio of the dyes) will allow investigating the relationship between the temporal and the spatial code, better spatial resolution (mainly limited by $z$-axis resolution, and therefore to be overcome with confocal or two-photon microscopy) will give access to the within-glomerulus organization, selective measurements of particular cell populations (for example, selectively staining PNs, as has been done for ORNs by Friedrich and Korsching) will give access to the components of the olfactory network, more glomeruli measured (mainly limited by the optical access to the structure) will give a more comprehensive picture of the spatial code. Furthermore, molecular biology and optical imaging can certainly join forces. For example, labelling glomeruli innervated by ORNs expressing a particular receptor gene with a tauGFP construct in mice and Drosophila will allow glomeruli to be morphologically identified prior to imaging, and allow their specific molecular response profile to be measured. Furthermore, expressing activity-dependent gene products in selected cell populations should allow the physiological mechanisms involved in olfactory processing to be dissected further using optical imaging.

Finally, it is important to relate the combinatorial code of glomerular activity to odour discrimination, odour evaluation and the hedonic nature of an odour. A behavioural analysis of the perceptual space of the honeybee has been started (Laska et al., 1999a). Discrimination matrices with many odours could be established effectively, allowing us to create the necessary data sets for multidimensional scaling methods and factor extraction. The multidimensional representation of odours in perceptual space could then be mathematically compared to the multidimensional representation of odours in the glomerular space. Is there an isomorphic function between the two spaces? Together with data from ORNs, it will become possible to describe and interpret the individual steps of the olfactory code on a neural basis-a far-ranging goal in odour research in general.

\section{Note added in proof}

The projection patterns of olfactory receptor neurons to the AL has now been described in Drosophila (Vosshall et al., 2000; Gao et al., 2000). The number of known expressed receptor genes is now 41. Each receptor neuron is likely to only express a single receptor gene. Axons from receptor cells expressing the same gene all converge onto a single or two identified glomeruli in each AL.

Calcium imaging has now also been reported from the Als of the moth Heliothis virescens (Galizia et al., in press); and also from the moth species Spodoptera littoralis (Hansson et al., 2000). "Notes added in proof" are too short to report the details.

\section{Acknowledgements}

We thank Silke Sachse, Jürgen Rybak, Dirk Müller, Anke Friedrich, Angelika Rappert, Ulrike Schröter, Daniel Wüstenberg, Jasdan Joerges and Armin Küttner for help in the discussions on an earlier version of the manuscript, and Mary Wurm for help with the English.

\section{References}

Abel, R., 1997. Das olfaktorische System der Honigbiene: elektrophysiologische und morphologische Charakterisierung von Antennallobus Neuronen und deren Beteiligung beim olfaktorischen Lernen. Ph.D. thesis, Freie Universität Berlin, Berlin.

Anton, S., Hansson, B., 1999. Physiological mismatching between neurons innervating olfactory glomeruli in a moth. Proc. R. Soc. London, Ser. B 266, 1813-1820.

Anton, S., Hansson, B.S., 1996. Antennal lobe interneurons in the desert locust Schistocerca gregaria (Forskal): processing of aggregation pheromones in adult males and females. J. Comp. Neurol. 370, 85-96.

Arnold, G., Masson, C., Budharugsa, S., 1985. Comparative study of the antennal lobes and their afferent pathway in the worker bee and the drone (Apis mellifera). Cell Tissue Res. 242, 593-605. 
Belluscio, L., Koentges, G., Axel, R., Dulac, C., 1999. A map of pheromone receptor activation in the mammalian brain. Cell 97, 209220.

Berg, B.G., Almaas, T.J., Bjaalie, J.G., Mustaparta, H., 1998. The macroglomerular complex of the antennal lobe in the tobacco budworm moth Heliothis virescens: specified subdivision in four compartments according to information about biologically significant compounds. J. Comp. Physiol. A 183, 669-682.

Blight, M.M., Pickett, J.A., Wadhams, L.J., Woodcock, C.M., 1995. Antennal perception of oilseed rape, Brassica napus (Brassicacea), volatiles by the cabbage seed weevil Ceuthorynchus assimilis (Coeoptera: Curcullionidae). J. Chem. Ecol. 21, 1649-1664.

Boeckh, J., Sandri, C., Akert, K., 1970. Sensorische Eingänge und synaptische Verbindungen im Zentralnervensystem von Insekten. Z. Zellforsch. 103, 429-446.

Brockmann, A., Brückner, D., 1995. Projection pattern of poreplate sensory neurones in honey bee worker, Apis mellifera L. (Hymenoptera: Apidae). Int. J. Insect Morphol. Embryol. 24, 405-411.

Bulfone, A., Wang, F., Hevner, R., Anderson, S., Cutforth, T., Chen, S. et al., 1998. An olfactory sensory map develops in the absence of normal projection neurons or GABAergic interneurons. Neuron 21, 1273-1282.

Christensen, T.A., Heinbockel, T., Hildebrand, J.G., 1996. Olfactory information processing in the brain: encoding chemical and temporal features of odors. J. Neurobiol. 30, 82-91.

Christensen, T.A., Hildebrand, J.G., 1987. Male-specific, sex pheromone-selective projection neurons in the antennal lobes of the moth Manduca sexta. J. Comp. Physiol. A 160, 553-569.

Christensen, T.A., Hildebrand, J.G., 1988. Frequency coding by central olfactory neurons in the sphinx moth Manduca sexta. Chem. Senses $13,123-130$.

Christensen, T.A., Hildebrand, J.G., 1997. Coincident stimulation with pheromone components improves temporal pattern resolution in central olfactory neurons. J. Neurophysiol. 77, 775-781.

Christensen, T.A., Waldrop, B.R., Hildebrand, J.G., 1998. Multitasking in the olfactory system: context-dependent responses to odors reveal dual GABA-regulated coding mechanisms in single olfactory projection neurons. J. Neurosci. 18, 5999-6008.

Cinelli, A.R., Hamilton, K.A., Kauer, J.S., 1995. Salamander olfactory bulb neuronal activity observed by video rate, voltage-sensitive dye imaging. III. Spatial and temporal properties of responses evoked by odorant stimulation. J. Neurophysiol. 73, 2053-2071.

Clyne, P.J., Warr, C.G., Freeman, M.R., Lessing, D., Kim, J., Carlson, J.R., 1999. A novel family of divergent seven-transmembrane proteins: candidate odorant receptors in Drosophila. Neuron 22, $327-338$.

Coopersmith, R., Leon, M., 1984. Enhanced neural response to familiar olfactory cues. Science 225, 849-851.

de Bruyne, M., Clyne, P.J., Carlson, J.R., 1999. Odor coding in a model olfactory organ: the Drosophila maxillary palp. J. Neurosci. 19, 4520-4532.

Delaney, K.R., Gelperin, A., Fee, M.S., Flores, J.A., Gervais, R., Tank, D.W. et al., 1994. Waves and stimulus-modulated dynamics in an oscillating olfactory network. Proc. Natl. Acad. Sci. U. S. A. 91, 669-673.

Delaney, K.R., Hall, B.J., 1996. An in vitro preparation of frog nose and brain for the study of odour-evoked oscillatory activity. J. Neurosci. Methods 68, 193-202.

Distler, P.G., Bausenwein, B., Boeckh, J., 1998. Localization of odorinduced neuronal activity in the antennal lobes of the blowfly Calliphora vicina: a $\left[{ }^{3} \mathrm{H}\right]$ 2-deoxyglucose labeling study. Brain Res. 805, 263-266.

Eckman, F.H., Freeman, W.J., 1990. Correlations between unit firing and EEG in the rat olfactory system. Brain Res. 528, 238-244.

Ernst, K.D., Boeckh, J., Boeckh, V., 1977. A neuroanatomical study on the organization of the central antennal pathways in insects. II.
Deutocerebral connections in Locusta migratoria and Periplaneta americana. Cell Tissue Res. 176, 285-308.

Faber, T., Joerges, J., Menzel, R., 1999. Associative learning modifies neural representations of odors in the insect brain. Nat. Neurosci. 2, 74-78.

Flanagan, D., Mercer, A.R., 1989a. An atlas and 3-D reconstruction of the antennal lobes in the worker honey bee, Apis mellifera $\mathrm{L}$. (Hymenoptera: Apidae). Int J. Insect Morphol. Embryol. 18, $145-159$.

Flanagan, D., Mercer, A.R., 1989b. Morphology and response characteristics of neurones in the deutocerebrum of the brain in the honeybee Apis mellifera. J. Comp. Neurol. 164, 483-494.

Fonta, C., Sun, X.J., Masson, C., 1993. Morphology and spatial distribution of bee antennal lobe interneurones responsive to odours. Chem. Senses 18, 101-119.

Free, J.B., 1987. Pheromones of Social Bees. Chapman \& Hall, London.

Friedrich, R.W., Korsching, S.I., 1997. Combinatorial and chemotopic odorant coding in the zebrafish olfactory bulb visualized by optical imaging. Neuron 18, 737-752.

Friedrich, R.W., Korsching, S.I., 1998. Chemotopic, combinatorial, and noncombinatorial odorant representations in the olfactory bulb revealed using a voltage-sensitive axon tracer. J. Neurosci. 18, 9977-9988.

Galizia, C.G., Joerges, J., Küttner, A., Faber, T., Menzel, R., 1997. A semi-in-vivo preparation for optical recording of the insect brain. J. Neurosci Methods 76, 61-69.

Galizia, C.G., Küttner, A., Joerges, J., Menzel, R., 2000. Odour representation in honeybee olfactory glomeruli shows slow temporal dynamics: an optical recording study using voltage sensitive dyes. J. Insect Physiol. 46, 877-886.

Galizia, C.G., McIlwrath, S.L., Menzel, R., 1999b. A digital threedimensional atlas of the honeybee antennal lobe based on optical sections acquired using confocal microscopy. Cell Tissue Res. 295, 383-394.

Galizia, C.G., Menzel, R., 2000. Odor perception in honeybees: coding information in glomerular patterns. Curr. Opin. Neurobiol. 10, 504-510.

Galizia, C.G., Menzel, R., Hölldobler, B., 1999c. Optical imaging of odour-evoked glomerular activity patterns in the antennal lobes of the ant Camponotus rufipes. Naturwissenschaften 86, 533-537.

Galizia, C.G., Nägler, K., Hölldobler, B., Menzel, R., 1998. Odour coding is bilaterally symmetrical in the antennal lobes of honeybees (Apis mellifera). Eur. J. Neurosci. 10, 2964-2974.

Galizia, C.G., Sachse, S., Rappert, A., Menzel, R., 1999a. The glomerular code for odor representation is species-specific in the honeybee Apis mellifera. Nat. Neurosci. 2, 473-478.

Galizia, C.G., Sachse, S., Mustaparta, H., in press. Calcium responses to pheromones and plant odours in the antennal lobe of the male and female moth Heliothis virescens. J. Comp. Physiol. A.

Gao, Q., Yuan, B., Chess, A., 2000. Convergent projections of Drosophila olfactory neurons to specific glomeruli in the antennal lobe. Nat. Neurosci. 3, 780-785.

Gelperin, A., 1994. Nitric oxide mediates network oscillations of olfactory interneurons in a terrestrial mollusc. Nature 369, 61-63.

Gelperin, A., Kleinfeld, D., Denk, W., Cooke, I.R.C., 1996. Oscillations and gaseous oxides in invertebrate olfaction. J. Neurobiol. $30,110-122$.

Gervais, R., Kleinfeld, D., Delaney, K.R., Gelperin, A., 1996. Central and reflex neuronal responses elicited by odor in a terrestrial mollusk. J. Neurophysiol. 76, 1327-1339.

Giurfa, M., 1993. The repellent scent-mark of the honeybee Apis mellifera ligustica and its role as communication cue during foraging. Insect Soc. 40, 59-67.

Giurfa, M., Nunez, J.A., 1992. Honeybees mark with scent and reject recently visited flowers. Oecologia 89, 113-117.

Guthrie, K.M., Anderson, A.J., Leon, M., Gall, C., 1993. Odor-induced 
increases in c-fos mRNA expression reveal an anatomical 'unit' for odor processing in olfactory bulb. Proc. Natl. Acad. Sci. U. S. A. $90,3329-3333$.

Guthrie, K.M., Gall, C.M., 1995. Functional mapping of odor-activated neurons in the olfactory bulb. Chem. Senses 20, 271-282.

Halter, S., Laissue, P.Ph., Stocker, R.F., 1998. The complex inner life of a glomerulus in the antennal lobe of Drosophila. ECRO XIII Siena Proceedings, p. 182

Hamilton, K.A., Kauer, J.S., 1989. Patterns of intracellular potentials in salamander mitral/tufted cells in response to odor stimulation. J. Neurophysiol. 62, 609-625.

Hammer, M., Menzel, R., 1998. Multiple sites of associative odor learning as revealed by local brain microinjections of octopamine in honeybees. Learn. Mem. 5, 146-156.

Hansson, B.S., Carlsson, M.A., Anton, S., 2000. Olfactory coding in the moth antennal lobe. 13th ISOT and 14th ECRO Brighton, proceedings pp. 107-108.

Heinbockel, T., Christensen, T.A., Hildebrand, J.G., 1999. Temporal tuning of odor responses in pheromone-responsive projection neurons in the brain of the sphinx moth Manduca sexta. J. Comp. Neurol. 409, 1-12.

Heinbockel, T., Kloppenburg, P., Hildebrand, J.G., 1998. Pheromoneevoked potentials and oscillations in the antennal lobes of the sphinx moth Manduca sexta. J. Comp. Physiol. A 182, 703-714.

Hildebrand, J.G., Shepherd, G.M., 1997. Mechanisms of olfactory discrimination: converging evidence for common principles across phyla. Annu. Rev. Neurosci. 20, 595-631.

Hölldobler, B., Wilson, E.O., 1990. The Ants. Springer Verlag, Berlin.

Imamura, K., Mataga, N., Mori, K., 1992. Coding of odor molecules by mitral/tufted cells in rabbit olfactory bulb. I. Aliphatic compounds. J. Neurophysiol. 68, 1986-2002.

Joerges, J., Küttner, A., Galizia, C.G., Menzel, R., 1997. Representations of odours and odour mixtures visualized in the honeybee brain. Nature 387, 285-288.

Johnson, B.A., Leon, M., 1996. Spatial distribution of $\left[{ }^{14} \mathrm{C}\right] 2$-deoxyglucose uptake in the glomerular layer of the rat olfactory bulb following early odor preference learning. J. Comp. Neurol. 376, $557-566$.

Johnson, B.A., Woo, C.C., Duong, H., Nguyen, V., Leon, M., 1995. A learned odor evokes an enhanced Fos-like glomerular response in the olfactory bulb of young rats. Brain Res. 699, 192-200.

Johnson, B.A., Woo, C.C., Hingco, E.E., Pham, K.L., Leon, M., 1999. Multidimensional chemotopic responses to $n$-aliphatic acid odorants in the rat olfactory bulb. J. Comp. Neurol. 409, 529-548.

Johnson, B.A., Woo, C.C., Leon, M., 1998. Spatial coding of odorant features in the glomerular layer of the rat olfactory bulb. J. Comp. Neurol. 393, 457-471.

Jourdan, F., Duveau, A., Astic, L., Holley, A., 1980. Spatial distribution of $\left[{ }^{14} \mathrm{C}\right] 2$-deoxyglucose uptake in the olfactory bulbs of rats stimulated with two different odours. Brain Res. 188, 139-154.

Kaissling, K.-E., 1997. Pheromone-controlled anemotaxis in moths. In: Lehrer, M. (Ed.), Orientation and Communication in Arthropods. Birkhauser Verlag, Basel, pp. 343-374.

Katoh, K., Koshimoto, H., Tani, A., Mori, K., 1993. Coding of odor molecules by mitral/tufted cells in rabbit olfactory bulb. II. Aromatic compounds. J. Neurophysiol. 70, 2161-2175.

Kauer, J.S., 1991. Contributions of topography and parallel processing to odor coding in the vertebrate olfactory pathway. Trends Neurosci. $14,79-85$.

Kauer, J.S., Senseman, D.M., Cohen, L.B., 1987. Odor-elicited activity monitored simultaneously from 124 regions of the salamander olfactory bulb using a voltage-sensitive dye. Brain Res. 418, 255-261.

Kleinfeld, D., Delaney, K.R., Fee, M.S., Flores, J.A., Tank, D.W., Gelperin, A., 1994. Dynamics of propagating waves in the olfactory network of a terrestrial mollusk: an electrical and optical study. J. Neurophysiol. 72, 1402-1419.
Kreissl, S., Eichmueller, S., Bicker, G., Rapus, J., Eckert, M., 1994. Octopamine-like immunoreactivity in the brain and suboesophageal ganglion of the honeybee. J. Comp. Neurol. 348, 583-595.

Laissue, P.P., Reiter, CH., Hiesinger, P.R., Halter, S., Fischbach, K.F., Stocker, R.F., 1999. Three-dimensional reconstruction of the antennal lobe in Drosophila melanogaster. J. Comp. Neurol. 405, $543-552$.

Lam, Y.W., Cohen, L.B., Wachowiak, M., Zochowski, M.R., 2000. Odors elicit three different oscillations in the turtle olfactory bulb. J. Neurosci. 20, 749-762.

Lancet, D., Greer, C.A., Kauer, J.S., Shepherd, G.M., 1982. Mapping of odor-related neuronal activity in the olfactory bulb by high-resolution 2-deoxyglucose autoradiography. Proc. Natl. Acad. Sci. U. S. A. $79,670-674$.

Laska, M., Freyer, D., 1997. Olfactory discrimination ability for aliphatic esters in squirrel monkeys and humans. Chem. Senses 22, $457-465$.

Laska, M., Galizia, C.G., Giurfa, M., Menzel, R., 1999a. Olfactory discrimination ability and odor structure-activity relationships in honeybees. Chem. Senses 24, 429-438.

Laska, M., Teubner, P., 1998. Odor structure-activity relationships of carboxylic acids correspond between squirrel monkeys and humans. Am. J. Physiol. 274, R1639-R1645.

Laska, M., Teubner, P., 1999. Olfactory discrimination ability for homologous series of aliphatic alcohols and aldehydes. Chem. Senses 24, 263-270.

Laska, M., Trolp, S., Teubner, P., 1999b. Odor structure-activity relationships compared in human and nonhuman primates. Behav. Neurosci. 113, 998-1007.

Laurent, G., 1996. Dynamical representation of odors by oscillating and evolving neural assemblies. Trends Neurosci. 19, 489-496.

Laurent, G., Davidowitz, H., 1994. Encoding of olfactory information with oscillating neural assemblies. Science 265, 1872-1875.

Laurent, G., Naraghi, M., 1994. Odorant-induced oscillations in the mushroom bodies of the locust. J. Neurosci. 14, 2993-3004.

Laurent, G., Wehr, M., Davidowitz, H., 1996a. Temporal representations of odors in an olfactory network. J. Neurosci. 16, 38373847.

Laurent, G., Wehr, M., MacLeod, K., Stopfer, M., Leitch, B., Davidowitz, H., 1996b. Dynamic encoding of odors with oscillating neuronal assemblies in the locust brain. Biol. Bull. 191, 70-75.

Lei, H., Hansson, B.S., 1999. Central processing of pulsed pheromone signals by antennal lobe neurons in the male moth Agrotis segetum. J. Neurophysiol. 81, 1113-1122.

Lieke, E.E., 1993. Optical recording of neuronal activity in the insect central nervous system: odorant coding by the antennal lobes of honeybees. Eur. J. Neurosci. 5, 49-55.

Lu, X.-C.M., Slotnick, B.M., 1998. Olfaction in rats with extensive lesions of the olfactory bulbs: implications for odor coding. Neuroscience 984, 849-866.

MacLeod, K.M., Laurent, G., 1996. Inhibitory mechanisms underlying oscillatory synchronization of projection neurons in the locust olfactory system. Soc. Neurosci. Abstr. 22, 1076-1076.

Malnic, B., Hirono, J., Sato, T., Buck, L.B., 1999. Combinatorial receptor codes for odors. Cell 196, 713-723.

Mellon, D.J., Wheeler, C.J., 1999. Coherent oscillations in membrane potential synchronize impulse bursts in central olfactory neurons of the crayfish. J. Neurophysiol. 81, 1231-1241.

Menzel, R., Müller, U., 1996. Learning and memory in honeybees: from behavior to neural substrates. Annu. Rev. Neurosci. 19, 379-404.

Mombaerts, P., 1996. Targeting olfaction. Curr. Opin. Neurobiol. 6, 481-486.

Mombaerts, P., Wang, F., Dulac, C., Chao, S.K., Nemes, A., Mendelsohn, M. et al., 1996. Visualizing an olfactory sensory map. Cell 87, 675-686. 
Mori, K., 1995. Relation of chemical structure to specificity of response in olfactory glomeruli. Curr. Opin. Neurobiol. 5, 467-474.

Mori, K., Mataga, N., Imamura, K., 1992. Differential specificities of single mitral cells in rabbit olfactory bulb for a homologous series of fatty acid odor molecules. J. Neurophysiol. 67, 786-789.

Mori, K., Nagao, H., Yoshihara, Y., 1999. The olfactory bulb: coding and processing of odor molecule information. Science 286, 711715 .

Mori, K., Yoshihara, Y., 1995. Molecular recognition and olfactory processing in the mammalian olfactory system. Prog. Neurobiol. 45, 585-619 [published erratum appears in Prog. Neurobiol. 46 (1995) 462].

Nunez, J., Almeida, L., Balderrama, N., Giurfa, M., 1997. Alarm pheromone induces stress analgesia via an opioid system in the honeybee. Physiol. Behav. 63, 75-80.

Pareto, A., 1972. Die zentrale Verteilung der Fühlerafferenz bei Arbeiterinnen der Honigbiene Apis mellifera L. Z. Zellforsch. 131, 109-140.

Rappert, A., Sachse, S., Galizia, C.G., Menzel, R., 1998. Representation of odour mixtures and their components in antennal lobes of Apis mellifera: results from chemically related stimuli. Eur J. Neurosci. (Suppl.) 10, 359.

Ressler, K.J., Sullivan, S.L., Buck, L.B., 1994. Information coding in the olfactory system: evidence for a stereotyped and highly organized epitope map in the olfactory bulb. Cell 79, 1245-1255.

Rodrigues, V., 1988. Spatial coding of olfactory information in the antennal lobe of Drosophila melanogaster. Brain Res. 453, 299307.

Rodrigues, V., Buchner, E., 1984. $\left[{ }^{3} \mathrm{H}\right] 2$-deoxyglucose mapping of odor-induced neuronal activity in the antennal lobes of Drosophila melanogaster. Brain Res. 324, 374-378.

Rodriguez, I., Feinstein, P., Mombaerts, P., 1999. Variable patterns of axonal projections of sensory neurons in the mouse vomeronasal system. Cell 97, 199-208.

Rospars, J.P., 1988. Structure and development of the insect antennodeutocerebral system. Int. J. Insect Morphol. Embryol. 17, 243294.

Rospars, J.P., Hildebrand, J.G., 1992. Anatomical identification of glomeruli in the antennal lobes of the male sphinx moth Manduca sexta. Cell Tissue Res. 270, 205-227.

Røstelien, T., Borg-Karlson, A.K., Fäldt, J., Jacobsen, U., Mustaparta, H., 2000. The plant sesquiterpene germacrene D specifically activates a major type of antennal receptor neurons of the tobacco budworm moth Heliothis virescens. Chem. Senses 25, 141-148.

Rubin, B.D., Katz, L.C., 1999. Optical imaging of odorant representations in the mammalian olfactory bulb. Neuron 23, 499-511.

Rubin, G.M., Yandell, M.D., Wortman, J.R., Gabor Miklos, G.L., Nelson, C.R., Hariharan, I.K. et al., 2000. Comparative genomics of the eukaryotes. Science 287, 2204-2215.

Sachse, S., Rappert, A., Galizia, C.G., 1999. The spatial representation of chemical structures in the antennal lobe of honeybees: steps towards the olfactory code. Eur. J. Neurosci. 11, 3970-3982.

Sallaz, M., Jourdan, F., 1993. C-fos expression and 2-deoxyglucose uptake in the olfactory bulb of odour-stimulated awake rats. NeuroReport 4, 55-58.

Sallaz, M., Jourdan, F., 1996. Odour-induced c-fos expression in the rat olfactory bulb: involvement of centrifugal afferents. Brain Res. $721,66-75$.

Schiffman, S.S., 1981. Characterization of odor quality utilizing multidimensional scaling techniques. In: Moskowitz, H.R., Warren, C.B. (Eds.), Odor Quality and Chemical Structure. American Chemical Society (ACS) Symposium Series 148. ACS, Washington, DC, pp. $1-21$.

Schürmann, F.W., Elekes, K., Geffard, M., 1989. Dopamine-like immunoreactivity in the bee brain. Cell Tissue Res. 256, 399-410.

Schürmann, F.W., Klemm, N., 1984. Serotonin-immunoreactive neurons in the brain of the honeybee. J. Comp. Neurol. 225, 570-580.
Shah, M., Persaud, K.C., Polak, E.H., Stussi, E., 1999. Selective and reversible blockage of a fatty acid odour response in the olfactory bulb of the frog (Rana temporaria). Cell. Mol. Biol. 45, 339-345.

Sharp, F.R., Kauer, J.S., Shepherd, G.M., 1975. Local sites of activity related glucose metabolism in rat olfactory bulb during olfactory stimulation. Brain Res. 98, 596-600.

Shepherd, G.M., 1987. A molecular vocabulary for olfaction. Ann. New York Acad. Sci. 510, 98-103.

Sigg, D., Thompson, C.M., Mercer, A.R., 1997. Activity-dependent changes to the brain and behavior of the honey bee, Apis mellifera (L.). J. Neurosci. 17, 7148-7156.

Singh, R.N., Nayak, S.V., 1985. Fine structure and primary sensory projections of sensilla on the maxillary palp of Drosophila melanogaster Meigen (Diptera: Drosophilidae). Int. J. Insect Morphol. Embryol. 14, 291-306.

Slotnick, B.M., Graham, S., Laing, D.G., Bell, G.A., 1987. Odor detection in rats with lesions of areas identified using the 2-deoxyglucose method. Ann. New York Acad. Sci. 510, 630-631.

Stewart, W.B., Kauer, J.S., Shepherd, G.M., 1979. Functional organization of rat olfactory bulb analysed by the 2-deoxyglucose method. J. Comp. Neurol. 185, 715-734.

Stocker, R.F., 1994. The organization of the chemosensory system in Drosophila melanogaster: a review. Cell Tissue Res. 275, 3-26.

Stopfer, M., Bhagavan, S., Smith, B.H., Laurent, G., 1997. Impaired odour discrimination on desynchronization of odour-encoding neural assemblies. Nature 390, 70-74.

Stopfer, M., Laurent, G., 1999. Short-term memory in olfactory network dynamics. Nature 402, 664-668.

Strausfeld, N.J., Hildebrand, J.G., 1999. Olfactory systems: common design, uncommon origins? Curr. Opin. Neurobiol. 9, 634-639.

Sun, X.-J., Fonta, C., Masson, C., 1993. Odour quality processing by bee antennal lobe interneurones. Chem. Senses 18, 355-377.

Tank, D.W., Gelperin, A., Kleinfeld, D., 1994. Odors, oscillations, and waves: does it all compute? Science 265, 1819-1820.

Teicher, M.H., Stewart, W.B., Kauer, J.S., Shepherd, G.M., 1980 Suckling pheromone stimulation of a modified glomerular region in the developing rat olfactory bulb revealed by the 2-deoxyglucose method. Brain Res. 194, 530-535.

Tømmerås, B.̊.., Mustaparta, H., 1987. Chemoreception of host volatiles in the bark beetle Ips typographus. J. Comp. Physiol. A 161, 705-710.

Tsuboi, A., Yoshihara, S., Yamazaki, N., Kasai, H., Asai-Tsuboi, H., Komatsu, M. et al., 1999. Olfactory neurons expressing closely linked and homologous odorant receptor genes tend to project their axons to neighboring glomeruli on the olfactory bulb. J. Neurosci. $19,8409-8418$.

Turin, L., 1996. A spectroscopic mechanism for primary olfactory reception. Chem. Senses 21, 773-791.

Vassar, R., Chao, S.K., Sitcheran, R., Nunez, J.M., Vosshall, L.B., Axel, R., 1994. Topographic organization of sensory projections to the olfactory bulb. Cell 79, 981-991.

Vickers, N.J., Christensen, T.A., Hildebrand, J.G., 1998. Combinatorial odor discrimination in the brain: attractive and antagonist odor blends are represented in distinct combinations of uniquely identifiable glomeruli. J. Comp. Neurol. 400, 35-56.

Vosshall, L.B., Amrein, H., Morozov, P.S., Rzhetsky, A., Axel, R., 1999. A spatial map of olfactory receptor expression in the Drosophila antenna. Cell 96, 725-736.

Vosshall, L.B., Wong, A.M., Axel, R., 2000. An olfactory sensory map in the fly brain. Cell 102, 147-159.

Wang, F., Nemes, A., Mendelsohn, M., Axel, R., 1998. Odorant receptors govern the formation of a precise topographic map. Cell 93 , $47-60$.

Wehr, M., Laurent, G., 1996. Odour encoding by temporal sequences of firing in oscillating neural assemblies. Nature 384, 162-166.

Winnington, A.P., Napper, R.M., Mercer, A.R., 1996. Structural plas- 
ticity of identified glomeruli in the antennal lobes of the adult worker honey bee. J. Comp. Neurol. 365, 479-490.

Woo, C.C., Coopersmith, R., Leon, M., 1987. Localized changes in olfactory bulb morphology associated with early olfactory learning. J. Comp. Neurol. 263, 113-125.
Yokoi, M., Mori, K., Nakanishi, S., 1995. Refinement of odor molecule tuning by dendrodendritic synaptic inhibition in the olfactory bulb. Proc. Natl. Acad. Sci. U. S. A. 92, 3371-3375. 